TRADUCCIÓN

\title{
Fiabilismo, inducción y escepticismo
}

\author{
David Papineau \\ King's College, London \\ david.papineau@kcl.ac.uk
}

El ensayo que se presenta a continuación constituye el capítulo 5 del libro de David Paipineau (1993) Philosophical Naturalism, Blackwell Ltd. Una versión previa de este texto —a la que aquí se añaden modificaciones sustantivas en lo que concierne a la reconstrucción filosófica de los métodos inductivos- apareció en enero de 1992, en The Philosophical Quarterly 42 (166), 1-20. Agradecemos la gentileza del profesor David Papineau al ceder los derechos para la presente traducción. En este ensayo expone y defiende los lineamientos de una epistemología basada en la fiabilidad como alternativa a la caracterización clásica, cartesiana, del conocimiento (basada en la certeza y en garantías subjetivas). A partir del esbozo de esta epistemología se propone, adoptando una metodología naturalista, una estrategia para responder a las objeciones escépticas en contra de las formas de inferencia no deductivas, en especial la inducción. A diferencia de otros partidarios de esta linea argumentativa, Papineau enfrenta de manera directa la frecuente acusación, por parte de sus antagonistas, de que la epistemología naturalista no responde al reto escéptico sino que sólo cambia de tema. La traducción fue realizada por Marc Jiménez Rolland. 


\section{Introducción}

Al final del capítulo $3^{1}$, indiqué que la teoría teleológica de la representación tiene consecuencias radicalmente antiverificacionistas. Los contenidos de la creencia son fijados por sus consecuencias para la acción, no por las circunstancias que llevaron a los que la creen a adoptarla. De modo que es perfectamente posible que un juicio deba tener una condición de verdad específica y aun así los seres humanos sean sistemáticamente propensos a formarse esta creencia cuando es falsa.

Podría pensarse que tal explicación realista ${ }^{2}$ de la representación abre la puerta al escepticismo: si las condiciones de verdad trascienden la evidencia, entonces ¿qué seguridad tenemos de que nuestras creencias están libres de error? En este capítulo quiero mostrar cómo esta amenaza escéptica al conocimiento puede afrontarse al interior de una perspectiva realista. Por consiguiente, en lo que sigue partiré de las implicaciones del capítulo 3 y asumiré, sin argumento adicional, que los juicios sobre el mundo natural responden a condiciones de verdad no verificacionistas. Me centraré aquí más bien en la noción de conocimiento y en cómo una comprensión adecuada de esta noción nos permite dar una respuesta adecuada al escepticismo, incluso dentro del marco conceptual de una teoría realista de la representación. Al inicio del siguiente capítulo, no obstante, volveré al debate general entre realismo y

\footnotetext{
${ }^{1}$ Se refiere al capítulo 3 «La teoría teleológica de la representación» de Philosophical Naturalism. Pese a que se hacen varias alusiones al resto del libro a lo largo de este capítulo, la línea argumentativa que se presenta en él es autocontenida y no presupone la previa lectura del resto del volumen para su cabal comprensión [Nota del traductor].

${ }^{2}$ Esta terminología se deriva de Dummett, quien introdujo el término «antirrealista» para las teorías del significado, de acuerdo a las cuales, la verdad no es trascendente a la evidencia (ver Dummett, 1978: 146ss).
} 
antirrealismo, y compararé mi actitud realista global hacia la representación y el conocimiento con la alternativa antirrealista.

En mayor detalle, el plan de este capítulo es el siguiente. Las secciones 2 a 8 defenderán una explicación fiabilista del conocimiento. Tales teorías fiabilistas son en la actualidad aceptadas con amplitud, pero un rasgo distintivo de mi defensa será su apelación al punto del concepto de conocimiento, más que a las intuiciones sobre casos. En las secciones 9 a 13 mostraré cómo esta explicación fiabilista del conocimiento proporciona una respuesta al problema escéptico tradicional de la inducción. Las secciones 14 a 17 generalizarán esta respuesta y evaluarán algunos otros argumentos a favor del escepticismo.

\section{Conocimiento y el proyecto de la investigación}

Comenzaré con una pregunta planteada en el capítulo 2 del libro de Bernard Williams, Descartes (1978). Williams pregunta: ¿por qué quieren conocimiento los seres humanos? Da por sentado, como lo haré yo, que los humanos quieren creencias verdaderas. Pero, como todos sabemos, una creencia puede ser verdadera y aun así no ser conocimiento, como cuando se trata de una corazonada o algún otro golpe de suerte. Así que el punto en cuestión es: ¿por qué queremos que nuestras creencias sean conocimiento, además de que sean verdaderas?

La respuesta de Williams es la siguiente. Los seres humanos son propensos a tener creencias falsas. Así que, si nuestro deseo de creencias verdaderas no ha de ser frívolo, requeriremos ejercitarnos para alcanzarlo. No es adecuado, no obstante, comenzar a comprobar cada una de las creencias con la intención de descartar las falsas. Tener una creencia es 
considerar a esa creencia verdadera. De modo que una vez que se han formado las creencias, la inspección interna no servirá para distinguir las verdaderas de las falsas. En la medida en que se es propenso al error, el daño ya habrá sido hecho.

La única manera efectiva para asegurarnos de que nuestras creencias son verdaderas es bloquear el error desde su fuente, al hacer que los procesos por los que adquirimos creencias en primer lugar sean unos que generalmente produzcan creencias verdaderas. De modo que Williams argumenta que el deseo mismo de creencias verdaderas genera el deseo de que nuestras creencias hayan de proceder de procesos que generalmente producen verdad. Y así, al encontrar independientemente plausible que las creencias producidas por tales procesos hayan de contar como conocimiento, Williams tiene una respuesta a su pregunta original sobre por qué hemos de querer conocimiento: nuestro deseo de conocimiento se deriva de nuestro deseo de evitar el error, y tener conocimiento es la única forma efectiva por la que los humanos pueden evitar el error.

Quisiera extraer algo más ambicioso de este análisis. Creo que, además de explicar por qué hemos de querer conocimiento, el relato de Williams también nos muestra lo que es el conocimiento. Williams da por hecho, desde fuera de su análisis, que las creencias generadas por procesos que producen verdad contarán como conocimiento. Pero creo que su relato también explica por qué tenemos este concepto de conocimiento, por qué seleccionamos creencias generadas por un proceso que produce verdad como conocimiento, como una clase especialmente buena de creencias. Mi idea aquí es que nuestra preocupación por evitar el error nos vuelve especialmente interesados en el estado al que requerimos llegar como medio para evitar el error, y que esta es la razón por la 
que llamamos a ese estado «conocimiento» —el estado, repito, de haber adquirido una creencia verdadera a partir de un proceso que generalmente produce creencias verdaderas ${ }^{3}$.

\section{Certeza y fiabilidad}

Las observaciones anteriores hacen surgir una pregunta de inmediato: ¿cómo ha de ser un proceso de formación de creencias que produzca verdades para ser una forma efectiva de evitar el error, y por ende para calificar como una fuente de conocimiento? En particular, ¿es suficiente que sea meramente fiable, en el sentido de que generalmente da lugar a creencias verdaderas como cuestión de hecho contingente en este mundo? ¿O acaso requiere además conllevar certeza, en el sentido de que debería ser imposible que una creencia resultado de ese proceso sea falsa? Gran parte del pensar filosófico tradicional asume que el conocimiento requiere certeza. Pero, desde el punto de vista de mis observaciones en la última sección, no está claro por qué la certeza ha de ser necesaria. El conocimiento, he sugerido, es el estado al que requerimos llegar si hemos de tener éxito en evitar el error. Pero habremos logrado este objetivo en tanto tengamos procesos formadores de creencias que sean fiables en este mundo. Que tales procesos nos

\footnotetext{
${ }^{3}$ Los casos Gettier muestran que necesitamos un requisito adicional. No sólo se debe adquirir una creencia verdadera a partir de un proceso que generalmente produce creencias verdaderas, sino que la verdad de la creencia no debe ser un accidente en relación con su ser producida por ese proceso. Este requisito adicional es el resultado natural de la hipótesis de que el conocimiento es un estado que es un medio para evitar el error, pues si la verdad de la creencia es un resultado de un accidente al estilo Gettier, entonces la evasión del error no será resultado de incorporar un proceso que conduzca a la verdad, en el sentido de que no será debido a que el proceso generalmente produce verdades que se habrá evitado el error. Más bien, será debido a una coincidencia afortunada (ver Williams, 1978: 43-4). Se requiere mayor análisis, por supuesto, para hacer precisa la noción relevante de accidente.
} 
llevarían por mal camino si las cosas fuesen diferentes no significa que nos llevarán por mal camino tal como son las cosas. Esta línea de pensamiento sugiere que la exigencia tradicional de certeza puede ser un error, quizá promovido por una concepción demasiado optimista de lo que el pensamiento humano puede lograr, pero no esencial al conocimiento mismo.

Más adelante, en la sección 5, volveré a la idea de que la exigencia de certeza puede ser un error. Pero primero, en el resto de esta sección y en la siguiente, diré un poco más acerca del contraste que he trazado entre fiabilidad y certeza. Nótese que he definido la certeza objetivamente, más que psicológicamente: la cuestión es si en efecto es imposible que un proceso formador de creencias específico produzca creencias falsas, no si el sujeto es consciente de ello, ni si implica alguna sensación de seguridad absoluta. Es esta noción objetiva la que importa para los argumentos de este capítulo. No obstante, hay conexiones obvias entre ella y los requisitos subjetivos del conocimiento, puesto que, como argumentó enérgicamente Descartes, la única fuente plausible de certeza en el sentido objetivo se deriva de varias operaciones de la mente consciente - en particular, de la introspección y la intuición. Y de este modo, si podemos obtener conocimiento con certeza objetiva, tendremos también, como de hecho ocurre, «garantías subjetivas» disponibles, en tanto que seremos siempre capaces de decir por introspección que nuestro conocimiento ha surgido de estas fuentes conscientes supuestamente infalibles.

En contraste, desde el punto de vista del fiabilismo (de aquí en delante usaré «fiabilismo» para referirme a la concepción de que sólo la fiabilidad es requerida para el conocimiento), cualesquiera requisitos subjetivos son gratuitos, 
puesto que, para que un proceso de formación de creencias sea fiable, no es necesario que su fiabilidad, o incluso su existencia, sea accesible a la conciencia. De acuerdo al fiabilismo, sabremos, digamos, que hay una mesa frente a nosotros, sólo en caso de que los procesos visuales inconscientes que dan lugar a tales creencias perceptuales generalmente produzcan creencias verdaderas, sea o no el caso que estemos conscientes de ello. No hay, por tanto, presión, dado el fiabilismo, para reconstruir tal conocimiento perceptual como involucrando primero cierta introspección infalible de alguna idea sensorial y luego cierta inferencia intuitivamente convincente a partir de esta idea de la presencia de una mesa. Si la exigencia de certeza en el conocimiento carece de motivación, entonces también carece de ella esta reconstrucción del conocimiento perceptual como involucrando inferencias infalibles a partir de introspecciones infalibles.

\section{Conocimiento y normatividad}

En ocasiones, se ha considerado que la epistemología fiabilista cambia de tema. Como he señalado atrás, el fiabilismo implica que sea o no el caso que tengamos conocimiento esto dependerá a menudo de cuestiones, tales como la fiabilidad de algunos procesos visuales, que residen fuera de nuestra conciencia. Pero esto parece implicar que estamos a merced de la naturaleza, que no podemos hacer nada para afectar el que tengamos o no conocimiento. $Y$ esto hace entonces a la epistemología fiabilista un asunto distinto de la versión tradicional (de aquí en adelante usaré «tradicional» para referirme a las concepciones de acuerdo a las cuales el 
conocimiento requiere certeza o garantías subjetivas) ${ }^{4}$, ya que, seguramente, una preocupación central de la epistemología tradicional fue la pregunta normativa de qué deberíamos hacer para asegurar que nuestras creencias son conocimiento.

No obstante, esta reacción hacia el fiabilismo involucra una falacia. Es verdad que las concepciones tradicionales del conocimiento ofrecen consejos sobre cómo obtener conocimiento, de manera tosca: que deberían monitorearse conscientemente los procesos de pensamiento y evitar cualesquiera que no sean necesariamente infalibles. $Y$ es verdad que el fiabilismo no coincide con este consejo. Pero esto no se debe a que el fiabilismo haya dejado de ofrecer consejos sobre cómo conocer, sino simplemente a que el fiabilismo ofrece consejos distintos.

Mientras los tradicionalistas aconsejan a los aspirantes al conocimiento que monitoreen lo que ocurre en sus mentes conscientes, los fiabilistas simplemente les recomendarán que lleven a cabo cualesquiera pasos sean requeridos para lograr que sus creencias provengan de procesos confiables. Tales pasos pueden requerir que influyamos en procesos que residen fuera de nuestra conciencia, pero ésa no es una razón para concluir que no podemos tener éxito. Después de todo, la mayoría de las cosas que influimos residen fuera de nuestra conciencia, como nuestros entornos, nuestra salud física, y así sucesivamente. De manera similar, no hay razón por la que no podamos influir en aspectos no conscientes de nues-

\footnotetext{
${ }^{4}$ ¿Qué hay de las diversas concepciones filosóficas, especialmente concepciones contemporáneas, que favorecen las garantías subjetivas, pero no la certeza? Tengo dos excusas para tratar a los dos requisitos en conjunto. Primero, no puedo pensar en una buena razón, en tanto opuesta a las intuiciones, a favor de la exigencia de garantías subjetivas, excepto como corolario del deseo de certeza. Segundo, la mayoría de mis argumentos se aplicarán tanto a la primera exigencia tomada por separado como a la segunda.
} 
tros procesos de formación de creencias, por medios tales como la memorización por repetición, ajustando el funcionamiento de instrumentos en los que confiamos, y así sucesivamente $^{5}$. (Los fiabilistas permitirán que el monitoreo consciente sea una forma de mejorar la fiabilidad de nuestros procesos de formación de creencias, pero no es la única forma).

Para evitar un posible malentendido, enfatizaré que no estoy sugiriendo que sea un requisito del conocimiento que los que conocen deban tomar pasos activos para producir que sus creencias sean conocimiento. Estoy consciente de que comencé este capítulo identificando el concepto de conocimiento como el estado al que alguien que, preocupado por evitar el error (un «investigador preocupado» [concerned] de aquí en adelante), quiere llegar como medio para evitar el error. Pero no se sigue de esto que la única manera de conocer sea tomar pasos activos para llegar a ese estado, puesto que se puede estar en el estado requerido, no debido a que se haya hecho algo para volver a los procesos de formación de creencias fiables, sino simplemente porque eran fiables desde el inicio. Tales conocedores pasivos estarán ya en el estado al que aspiran los investigadores preocupados, incluso si no comparten la preocupación por llegar a ese estado 6 .

\footnotetext{
${ }^{5}$ Para más sobre la medida en que podemos alterar nuestros procesos de formación de creencias no conscientes, ver mi Reality and Representation (1987; caps. 7.4, 7.6).

${ }^{6}$ Quizá los conocedores pasivos tengan al menos esto en común con los investigadores preocupados: sus procesos de formación de creencias no sólo sucede que son fiables, sino que deben estar presentes debido a que son fiables. Esta sugerencia descartará fiabilidad meramente fortuita, pero permitirá fiabilidad debida a la evolución, el aprendizaje y la educación, junto con el caso en el que los investigadores preocupados adoptan procesos debido a que conscientemente reconocen la fiabilidad de esos procesos. Esta sugerencia también indica una posible respuesta a la delicada cuestión acerca de cómo individuar procesos de formación de creencias con el fin de evaluar su fiabilidad: a saber, como una primera aproximación, hemos de individuarlos por las mismas características en tanto son requeridas para explicar su adopción (ver Papineau, 1987: 136-8).
} 
Razones contra intuiciones

Acabo de argumentar que el fiabilismo no abandona la cuestión normativa tradicional de cómo es mejor adquirir conocimiento. En esta sección quiero considerar un argumento más bien distinto para pensar que el fiabilismo cambia el tema. Este no apela a consideraciones de normatividad, sino directamente a intuiciones acerca del conocimiento. Muchos filósofos consideran que es intuitivamente obvio que las garantías subjetivas son parte del concepto de conocimiento. De modo que concluyen que el fiabilismo, que prescinde de tales requisitos, debe estar equivocado.

Mi respuesta a esto es que las intuiciones no son la única manera de evaluar una teoría del conocimiento. Hay una vasta literatura contemporánea que intenta decidir entre el fiabilismo y las teorías tradicionales únicamente apelando a intuiciones sobre ingeniosos casos (ver Shope, 1983). Sin embargo y desafortunadamente, estas intuiciones apuntan en ambas direcciones y la literatura basada en ellas es notoriamente indecisa. En contraste, mi aproximación en este ensayo no ha apelado a intuiciones, pero ha intentado identificar un concepto subyacente de conocimiento, al localizar el papel que desempeña en nuestro pensamiento, al intentar comprender por qué el conocimiento es una cuestión de interés para los seres humanos.

Mi sugerencia ha sido que el conocimiento está ligado a nuestro deseo de evitar creencias falsas: es el estado al que un investigador preocupado debe llegar con el fin de alcanzar su deseo. Dada esta identificación del concepto de conocimiento, por así decirlo, podemos entonces investigar concepciones más detalladas, o llamémoslas teorías, de lo que ese estado es, teorías más detalladas acerca de cuál sea 
exactamente el estado al que un investigador activo requiere llegar con el fin de evitar el error. La teoría que defiendo es que el estado que se requiere consiste en haber adquirido una creencia a partir de procesos confiables. La teoría de que la certeza y, por ende, las garantías subjetivas son requeridas es una teoría distinta, pero aún así es una teoría (en la terminología que empleo) sobre el mismo concepto de conocimiento.

Es por eso que pienso que, cualesquiera que sean las intuiciones que favorezcan a la teoría tradicional por encima de la alternativa fiabilista, no son decisivas. Si he mostrado que la teoría fiabilista es la teoría correcta, en tanto que adquirir una creencia a partir de un proceso fiable es en efecto lo que se requiere con el fin de evitar el error, entonces he mostrado con ello que la teoría tradicional y las intuiciones que la apoyan están equivocadas.

Quizá aún quede un hueco aquí. Supóngase que se concede que he identificado el concepto subyacente de conocimiento exitosamente y que he mostrado que el fiabilismo es la teoría del conocimiento que mejor se ajusta a él. Una pregunta obvia que surge entonces es por qué alguien habría tenido ideas contrarias acerca de la certeza y las garantías subjetivas en primer lugar. Ya que, tal como lo he relatado, el fiabilismo, en tanto opuesto a la teoría tradicional, se sigue muy rápidamente del concepto de conocimiento, volviendo misteriosa la razón por la que alguien habría pensado que alguna cosa más era necesaria. No podemos simplemente quedarnos con la sugerencia, ofrecida brevemente y de paso con anterioridad, de que las ideas tradicionales acerca del conocimiento pueden haber sido promovidas por un excesivo optimismo acerca de lo que puede obtenerse, puesto que la posibilidad de obtener algo no explica por qué deberíamos quererlo, si no es de antemano deseable. 
Volveré a este asunto en la sección 8, pero primero permítaseme comentar brevemente las similitudes entre la estrategia esbozada en esta sección y la defendida por Edward Craig en The Practical Explication of Knowledge (1986). En un nivel detallado, la concepción de Craig difiere de la mía: él ofrece una explicación de tercera persona del concepto de conocimiento en contraste con mi explicación de primera persona, argumentando que el conocimiento es el estado en el que requieren estar nuestros informantes para que nosotros evitemos el error, no el estado en el que nosotros requerimos estar. Pero en el nivel de la estrategia general, Craig y yo estamos de acuerdo, puesto que él busca ofrecer una explicación sobre el concepto de conocimiento y usar esta explicación para dar cuenta de la naturaleza del concepto, más que sólo tratar de identificar el concepto a partir únicamente de intuiciones.

En cuanto a nuestras diferencias, mi objeción a la línea de Craig sería que él, en efecto, se centra en el caso especial en el que tenemos éxito al evitar el error adquiriendo creencias de informantes que tienen éxito al evitar el error. Acepto que este caso especial podría ser de importancia primordial en el desarrollo histórico del concepto cotidiano de conocimiento, en tanto que preocuparse acerca de la fiabilidad de nuestros informantes exige menos sofisticación que preocuparse acerca de la propia fiabilidad (Craig, 1986: 215). Pero, aun así, el enfoque de Craig en la tercera persona me parece que tiene la desventaja de cortar el vínculo con la cuestión normativa tradicional de qué deberíamos hacer para evitar el error. Esto es, incluso si es injusto con la historia del concepto de conocimiento ver el deseo de buenos informantes como un caso especial de un deseo general de tener buenos procesos de formación de creencias, yo argumentaría que la perspectiva más general que he adoptado tiene, sin embar- 
go, la ventaja de mostrar cómo el concepto de conocimiento se relaciona con preocupaciones filosóficas familiares acerca del conocimiento.

\section{Conocimiento y porcentajes}

¿Qué tanta fiabilidad debería exigir del conocimiento un fiabilista? Consideraré dos dimensiones de esta pregunta. Primero, consideraré si necesitamos cien por ciento de fiabilidad, o si algún porcentaje menor, como noventa y cinco por ciento, digamos, es suficiente. En segundo lugar, indagaré sobre qué rango de posibilidades ha de ser evaluado el porcentaje relevante.

En torno a la cuestión del porcentaje, sería un error pensar que el rechazo de la certeza ha decidido esta cuestión a favor de alguno menor a cien por ciento. Puesto que «certeza», como la he estado usando, implica que un proceso de formación de creencias no puede errar, entregará cien por ciento de creencias verdaderas en todos los mundos posibles. Éste es un requisito mucho mayor que cien por ciento de fiabilidad en este mundo. Así que podemos rechazar la certeza y aún así sostener un requisito de cien por ciento de fiabilidad contingente. Por otro lado, incluso esto último parece un requisito bastante fuerte. De modo que quizá hemos de considerar argumentos a favor de algún porcentaje menor.

Acerca de la segunda cuestión, sobre el rango de posibilidades, el argumento hasta el momento ha mostrado que sería un error requerir que este grado de fiabilidad se mantenga a través de todos los mundos posibles. Pero, como veremos, hay aún razones para querer que se mantenga a través de al menos algunas situaciones contrafácticas. 
Me ocuparé primero de la cuestión de los porcentajes. Volveré a la cuestión sobre el rango de posibilidades en la siguiente sección. Hasta cierto punto, es posible eludir la cuestión de los porcentajes. Supóngase que un proceso específico de formación de creencias produce creencias que son verdaderas en noventa y cinco por ciento de las ocasiones. Luego, el resultado apropiado de ese proceso no sería una creencia completa en todo caso, sino un 0.95 de grado de creencia. Después de todo, si crees que lloverá mañana sobre la base de un método de pronóstico noventa y cinco por ciento fiable, sería poco recomendable apostar un millón de libras en contra de un centavo, o jugarse más de diecinueve a uno a que lloverá mañana. De modo que si el conocimiento sin calificativos requiere creencia, como he asumido implícitamente desde el inicio, entonces esto parece apelar a procesos de formación de creencias que den lugar a verdades con el cien por ciento de fiabilidad.

Aun así, quizá es un poco pronto para asumir que el conocimiento requiere estrictamente una creencia completa. Después de todo, en el discurso cotidiano ciertamente nos referimos a creencias con alto grado de fiabilidad, aunque menor cien por ciento, como «creencias» simpliciter, y en esa medida hemos de esperar que la noción de conocimiento también se aplique a creencias suficientemente bien fundadas con un alto grado, mas no completa. Pero, dicho esto, hay entonces una respuesta obvia a la pregunta de cuán bien fundada requiere estar tal creencia con un alto grado, mas no completo, para ser calificada como conocimiento, puesto que, bajo la sugerencia presente, el discurso cotidiano tiene ciertos estándares (que quizá varían de contexto a contexto) de cuán firmemente se ha de sostener una creencia para ser calificada como una creencia simpliciter. De modo que, 
¿por qué no incorporar esos estándares en nuestro análisis del conocimiento, y decir que para que una creencia sea conocimiento debe provenir de un proceso cuya fiabilidad es al menos suficiente para garantizar el grado de confianza requerido para que una creencia califique como una creencia simpliciter en primer lugar, y no sólo como lo que incluso en el discurso cotidiano se consideraría una creencia parcial?

Sería útil para lo que sigue, observar que aunque es ciertamente verdadero que a menudo permitimos que creencias con menos que un grado estrictamente completo se califiquen como conocimiento, hay también un sentido práctico en el que es siempre mejor obtener una creencia de procesos cien por ciento fiables. Para ponerlo de manera simple, la razón es que tales creencias serán entonces verdaderas y las decisiones informadas por ellas tendrán éxito con probabilidad uno, mientras que si aquellas creencias provienen de procesos con fiabilidad menor a cien por ciento, las acciones que informan tendrán menor probabilidad de tener éxito.

De hecho, esto plantea el asunto de manera demasiado simple, puesto que incluso si las creencias son pruebas en contra del error, pueden aun así no ser lo suficientemente informativas, puede no realizarse la inferencia correctamente. Pero estas dos advertencias se aplicarían de igual manera incluso si el mismo conjunto de creencias proviene de procesos menos fiables que cien por ciento, y por ende ello no afecta al hecho de que es siempre preferible, con vistas a la realización de nuestros deseos, obtener creencias completas de un proceso a cien por ciento, en vez de algo menor que una creencia estrictamente completa de un proceso menos fiable.

Debería también admitirse que en muchos casos los costos adicionales de obtener fiabilidad a cien por ciento no serían compensados por la probabilidad adicional de éxito, en cuyo 
caso haríamos mejor en contentarnos con una creencia parcial. Esta es, sin duda, la razón por la que el discurso cotidiano no hace de una creencia estrictamente completa una precondición para el conocimiento en general. Pero esto requiere meramente una calificación adicional y aun así no afecta al hecho subyacente de que, cuando los costos son iguales, la creencia que se deriva de procesos cien por ciento fiables es siempre mejor ${ }^{7}$.

\section{Mundos posibles cercanos}

Pasaré ahora al segundo problema que surgió al inicio de esta sección: ¿qué rango de posibilidades es relevante para la fiabilidad de procesos de formación de creencias? A primera vista parecería seguirse de la totalidad de mi argumento que la fiabilidad en el mundo actual es todo lo que importa. Después de todo, como observé antes, la fiabilidad en este mundo es todo lo que requerimos para evitar el error. No obstante, hay buenas razones por las que el conocimiento exige más que meramente esta fiabilidad de-este-mundo.

Volvamos a la idea de que el conocimiento es el estado al que los investigadores preocupados deben llegar para evitar el error. Es verdad que los investigadores preocupados no tienen interés en la fiabilidad en mundos no-actualizados como tales. Sin embargo, al adquirir procesos que son fiables en este mundo, los investigadores preocupados inevitable-

\footnotetext{
${ }^{7}$ Asumo aquí creencias acerca de asuntos en los que no interviene el azar. Donde azares genuinos no unitarios están involucrados, el mejor grado de creencias acerca de cualquier resultado será, por supuesto, distinto de uno. Pero incluso aquí será siempre mejor tener creencias verdaderas de grado completo acerca del azar, costos de la formación de creencias aparte, pues tales creencias asegurarán entonces que, en general, las decisiones maximizan las posibilidades objetivas de éxito.
} 
mente adquirirán procesos que son fiables también en un rango de situaciones no-actualizadas.

La razón es que, si eres un investigador preocupado, no serás capaz de anticipar el futuro con suficiente detalle para ser capaz de decir exactamente qué verdades requiere producir ese proceso para ser fiable en el mundo actual. En vez de eso, inevitablemente tendrás sólo un conocimiento limitado acerca de la naturaleza general del mundo y tu situación particular en él ${ }^{8}$, información que estrechará el rango de circunstancias en las que puedes encontrarte en el futuro, pero ciertamente no te dirá con exactitud cuáles serán. De modo que, al buscar procesos de formación de creencias fiables, inevitablemente te verás obligado a buscar procesos de formación de creencias que produzcan fiablemente creencias verdaderas a través del rango entero de posibles circunstancias en las que podrás encontrarte de acuerdo a la información disponible. Puesto que no todas las posibilidades en ese rango serán actuales, inevitablemente buscarás llegar al estado que produzca creencias verdaderas en varios mundos posibles cercanos, así como en el mundo actual.

De modo que mi aproximación completa al conocimiento se ajusta al requisito de que el conocimiento debería tener cier-

\footnotetext{
${ }^{8}$ Algunos lectores estarán descontentos con estas suposiciones acerca del conocimiento disponible para los investigadores preocupados. Hay dos posibles inquietudes aquí, una acerca de una posible circularidad por mi parte, la otra acerca de una posible circularidad por parte de los investigadores preocupados. Si se está inquieto sobre una circularidad por mi parte, observaré que mi preocupación actual no es tanto definir el conocimiento, como identificar el papel que el concepto desempeña en nuestro pensamiento: creo que es útil en esta tarea considerar el predicamento de un investigador preocupado que ya tiene algún conocimiento; sería una tarea adicional, que no intentaré aquí, y que en efecto descartaría la mención al conocimiento de los investigadores preocupados, especificar condiciones necesarias y suficientes, en términos no epistemológicos, para que alguien tenga conocimiento. $\mathrm{Si}$, por otra parte, se tienen inquietudes acerca de alguna clase de circularidad por parte del investigador preocupado, sobre la base, quizá, de que cualquier investigador seriamente preocupado debería empezar por no suponer nada, entonces la inquietud debería saciarse por los puntos señalados más abajo, en las secciones 11 a 13.
} 
to grado de fiabilidad contrafáctica. Nótese, no obstante, que esto sigue siendo un requisito mucho menor que el de fiabilidad en todos los mundos posibles, puesto que la información de la que disponen los investigadores preocupados será, en general, suficiente para desechar la posibilidad de que estén en la mayoría de los mundos posibles (tales como el mundo donde uno es manipulado por el genio maligno de Descartes) o incluso en la mayoría de los mundos causalmente posibles (como el mundo en el que uno es un cerebro en una cubeta) ${ }^{9}$.

\section{Los atractivos de la certeza}

Prometí volver a la cuestión de por qué la certeza debería ser un requisito intuitivamente plausible como requisito para el conocimiento. Una respuesta seria a esta cuestión incluiría una dimensión histórica, examinar el desarrollo de las nociones epistemológicas occidentales con particular referencia a la distinción medieval entre demostración y opinión, las luchas en los siglos XVII y XVIII por encontrar un lugar dentro de esta distinción para el conocimiento científico recién surgido y, quizá las más importantes de todas, las dimensiones religiosas que también animaban a los participantes en estos debates. No obstante, una investigación de tal índole está más allá del alcance de este libro. En su lugar ofreceré una posible

\footnotetext{
${ }^{9}$ Craig (1986: 218-21) argumenta de manera similar a partir de la situación informativa limitada de un investigador preocupado hacia el requisito contrafáctico para el conocimiento. Pero él está preocupado por la clase de fiabilidad contrafáctica que queremos de nuestros informantes, dada nuestra limitada información acerca de la situación particular en cuestión, mientras que yo estoy interesado en la fiabilidad contrafáctica que esperamos de nosotros mismos, dada nuestra información general limitada acerca de las situaciones en las que estaremos. El grado preciso de fiabilidad contrafáctica requerido para el conocimiento es un tema complejo, sobre el que no abundaré más aquí, con la excepción de que señalaré que ésta es un área en la que una buena razón teórica me parece que vale lo que mil sutiles intuiciones.
} 
explicación filosófica de la influencia de la certeza, no como una explicación histórica en competencia, sino como un posible complemento de ella.

Acabo de argumentar que el conocimiento requiere no sólo fiabilidad en el mundo actual, sino fiabilidad a través de todos los mundos que son posibles, en relación a la información disponible a los investigadores preocupados. No obstante, al discutir el tema de la fiabilidad contrafáctica, he dado por sentado implícitamente que nuestros investigadores preocupados están buscando creencias completas de procesos cien por ciento fiables. Pero, como vimos antes, en muchos contextos prácticos será a menudo más eficiente conformarse con menos que creencias completas, producidas por procesos de formación de creencias de fiabilidad alta, pero menos que perfecta.

Ahora bien, un investigador que estuviese preocupado por adquirir tal creencia menor que completa tendría derecho a ignorar, al evaluar la fiabilidad de los procesos relevantes de formación de creencias, no sólo cualquier mundo que cayera bajo el umbral apropiado de probabilidad relativa a la información disponible. Pues claramente el hecho de que los procesos serían poco fiables en tales circunstancias improbables no le da al investigador preocupado razón suficiente para retener un alto grado de creencia a partir de sus deliberaciones.

Añádase a este último punto la consideración, elaborada en la sección 6, de que, aunque es perfectamente razonable conformarse meramente con un alto grado de creencia, es siempre mejor, especialmente donde es importante no equivocarse en las acciones, obtener creencias completas de procesos cien por ciento fiables. Al reunir estos dos puntos, se sigue que el conocimiento se volverá mejor entre más sean 
las circunstancias posibles con cualquier probabilidad distinta de cero a través de las que los procesos de formación de creencias sean fiables.

Esto, por supuesto, no constituye un buen argumento para pensar que lo mejor sería adquirir creencias a partir de procesos que sean fiables en todos los mundos posibles. Incluso si es bueno ser fiable a través de todos los mundos con probabilidad distinta de cero en relación con el conocimiento disponible, esto es muy poco en comparación con la fiabilidad en todos los mundos posibles, pues, como he señalado, la mayoría de las circunstancias serán totalmente imposibles en relación con la información disponible para cualquier investigador preocupado. Sin embargo, puede verse cómo sería fácil deslizar la cuestión, a partir de la idea de que se requiere estar idóneamente prevenido en contra de cualesquiera posibilidades que la información permita con cualquier probabilidad distinta de cero, a la idea de que se requiere estar idóneamente prevenido en contra de cualesquiera posibilidades.

¿El problema de la inducción? ¿Cuál problema?

Paso ahora al problema de la inducción. Supongamos, por el bien del argumento, que la forma general de la inducción es la enumeración simple. (No creo que éste sea realmente un buen modelo para las inferencias inductivas, pero ayudará a la exposición asumir, por el momento, que lo es). De modo que, por ejemplo, a partir de la premisa: «N cuervos han sido negros hasta el momento», concluimos que todos los cuervos son negros. Esquemáticamente: 


$$
\begin{array}{r}
\mathrm{Fa}_{1} \& \mathrm{Ga}_{1} \\
\ldots \\
\mathrm{Fa}_{\mathrm{N}} \& \mathrm{Ga}_{\mathrm{N}} \\
\forall x(\mathrm{~F} x \stackrel{\mathrm{G} x}{\longrightarrow})
\end{array}
$$

La objeción tradicional a esta forma de inferencia es que es lógicamente inválida. La conclusión no se sigue lógicamente de las premisas. Es lógicamente posible que las premisas sean verdaderas pero que la conclusión sea falsa. Para los fiabilistas, no obstante, esta objeción no tiene fuerza. Puesto que una forma de inferencia puede ser contingentemente fiable sin estar lógicamente justificada, los fiabilistas pueden simplemente responder a la objeción tradicional diciendo que el carácter no lógico de las inferencias inductivas no es una razón para negar que tales inferencias produzcan conocimiento.

Quizá valga la pena detenerse brevemente para explicar cómo la noción de fiabilidad se aplica a las inferencias. Aunque no he tratado esto explícitamente hasta el momento, la noción apropiada es obviamente la de fiabilidad condicional: la conclusión debe ser siempre verdadera en el mundo actual, si las premisas lo son. (Esto asegurará, entonces, para un fiabilista, que las inferencias fiables transmitirán conocimiento y que producirán conclusiones conocidas cuando se apliquen a premisas conocidas, puesto que si las premisas son conocidas, en el sentido de que son verdaderas y se ha llegado fiablemente a ellas, entonces cualquier conclusión derivada a partir de una inferencia condicionalmente fiable será también verdadera, se llegará a ella fiablemente, y será así conocida).

Es tentador abandonar el problema de la inducción aquí, con la observación de que la invalidez lógica de la inferencia no significa que sus conclusiones no sean conocimiento. 
No obstante, sospecho que la mayoría de los lectores no serán disuadidos tan rápidamente del escepticismo inductivo, incluso si son persuadidos por los argumentos generales a favor del fiabilismo. De modo que en las siguientes secciones consideraré si hay razones adicionales por las que los fiabilistas debieran estar preocupados acerca de la inducción. En consecuencia, daré por sentado que el fiabilismo es la explicación correcta del conocimiento en general. El tema a considerar es si alguna duda escéptica surge aun sobre la inducción dentro de esta suposición.

\section{¿Es fiable la inducción?}

Una posible preocupación acerca de la simple respuesta del fiabilista al problema de la inducción esbozada en la sección anterior es que parece similar a la «justificación analítica de la inducción», propuesta por Edwards (1949) y Strawson (1952: cap. 9). Aun así, ahora se acepta ampliamente que no es posible mostrar que las inferencias inductivas son legítimas simplemente observando, como lo hace la «justificación analítica», que la mayoría de las personas caracterizarían a la inducción como un caso central del pensamiento «racional». Puesto que tales hechos sobre el uso común dejan abierta la posibilidad de que haya requisitos subyacentes (que de hecho no son satisfechos por la inducción) para que una forma de razonamiento sea racional, entonces la mayoría de la gente puede estar en el error al sostener que la inducción es racional.

No obstante, la respuesta fiabilista a la inducción es bastante distinta a la justificación analítica. Los fiabilistas no aceptan una forma de razonamiento como racional sólo debido a que es ampliamente considerada como «racional», sino 
sólo en la medida en que satisfaga el requisito subyacente de producir verdades fiables ${ }^{10}$. En particular, los fiabilistas considerarán fiable a la inducción, y por ende a sus conclusiones conocimiento, no debido a que se le denomine «racional», sino puesto que ellos creen que es en efecto un método fiable para obtener verdades nuevas a partir de viejas verdades.

No obstante, esto apunta ahora a un problema obvio. Que la inducción genera fiablemente verdades es por sí misma una afirmación sustantiva contingente. Incluso así, no se ha ofrecido aún apoyo para esto. Nosotros, amigos fiabilistas de la inducción, parece que simplemente estamos dando por sentado que la inducción es un método fiable de inferencia y luego concluyendo, en virtud de nuestro fiabilismo general acerca del conocimiento, que la inducción produce conocimiento. Pero, ¿qué base tenemos para la suposición inicial de que la inducción es fiable?

Algunos fiabilistas están inclinados a responder, en este punto del procedimiento, que no necesitamos saber que sabemos para saber (ver Van Cleve, 1984: 559, 562) ${ }^{11}$. Creo que éste es un movimiento erróneo. Es perfectamente verdadero, por supuesto, que los que no son filósofos y poseen conocimiento no requieren saber que saben. Pero la exigencia actual de una defensa de la afirmación de que la inducción produce conocimiento, no se refiere a las personas ordinarias

\footnotetext{
${ }^{10}$ Esta afirmación merece quizá discusión adicional. Algunos fiabilistas sostendrían que, mientras la fiabilidad es suficiente para el conocimiento, alguna clase de garantía subjetiva adicional es necesaria para la racionalidad. Desde mi perspectiva, no obstante, los argumentos acerca del conocimiento se extienden a la racionalidad. Para una defensa de un punto análogo acerca de la «justificación» ver Goldman, 1979.

${ }^{11}$ Parte importante de mi siguiente defensa de la inducción está influenciada por el importante artículo de Van Cleve. No obstante, en el pasaje referido, Van Cleve parece negar que los fiabilistas requieran defender la fiabilidad de la inducción, sobre la base de que la fiabilidad es un requisito «externo». Esto me parece un infortunado desliz, dado que las evaluaciones de las defensas fiabilistas de la inducción son altamente razonables para juicios previos de lo que exactamente el fiabilista requiere hacer.
} 
que poseen conocimiento y utilizan la inducción, sino más bien a nosotros los filósofos que hablamos de inducciones y en particular acerca de la cuestión de si la inducción produce conocimiento. Nosotros, amigos fiabilistas de la inducción, estamos explícitamente afirmando que las inferencias inductivas producen conocimiento puesto que producen fiablemente verdades. Dado esto, es perfectamente razonable que alguien nos rete a que brindemos apoyo para esta afirmación.

Por supuesto, si no logramos cumplir este reto, ello no necesariamente mostrará que la inducción no produce conocimiento. Carecer de fundamentos para aceptar la fiabilidad de la inducción no es lo mismo que tener fundamentos para negarla. Pero tal postura sería una falla para nosotros, amigos de la inducción, y un éxito para nuestros rivales escépticos. El punto en cuestión es si la inducción produce conocimiento, esto es, dado el fiabilismo, si la inducción produce fiablemente verdades. Nosotros, amigos de la inducción, decimos que sí; nuestros rivales escépticos solicitan apoyo para esta afirmación. Si no podemos responderles, entonces ellos habrán tenido éxito en mostrar que no tenemos derecho a adoptar esta postura.

De modo que para conservar la inducción como una fuente de conocimiento necesitamos mostrar que las inferencias inductivas son fiables. No obstante, ahora que tenemos clara esta necesidad, no creo que sea difícil satisfacerla. La forma obvia de descubrir si la inducción es fiable es examinar la evidencia que conlleva la cuestión. Cuando las personas hacen inducciones, ¿resultan sus conclusiones verdaderas? Hay muchos ejemplos pasados de gente que hace inducciones. Y una vez que las han hecho, sus conclusiones han resultado en efecto verdaderas. De modo que tenemos 
todas las razones para sostener que, en general, las inferencias inductivas producen verdades. Esto es:

(2) Cuando la persona indujo, de $\mathrm{N}$ observaciones de A en compañía de B, que todos los As son Bs, esta conclusión fue verdadera. Cuando la persona ${ }_{2}$ indujo, de $\mathrm{N}$ observaciones de $\mathrm{C}$ acompañadas de $\mathrm{D}$, que todos los Cs son Ds, esta conclusión ${ }_{2}$ fue verdadera.

Cuando la persona ${ }_{\mathrm{N}}$ indujo, de $\mathrm{N}$ observaciones de $\mathrm{L}$ acompañadas de $\mathrm{M}$, que todos los Ls son Ms, esta conclusión ${ }_{\mathrm{N}}$ fue verdadera.

Siempre que alguien hace una inducción, su conclusión es verdadera.

\section{La legitimidad de los métodos normales}

Permítaseme primero dejar de lado dos inquietudes obvias acerca de las premisas de este argumento. En primer lugar, ¿no hay acaso muchos ejemplos de inducciones no exitosas con conclusiones falsas, así como de inducciones exitosas con conclusiones verdaderas? En segundo lugar, ¿cómo podemos incluso saber que las inducciones exitosas lo son, dado que la observación del pasado sólo mostrará, por ejemplo, que los As han sido Bs hasta el momento, no que todos los As son Bs? Enfrentaré estos dos puntos en su debido momento (en la sección 17 y en la nota 14 respectivamente). Pero por ahora será útil ignorarlos y atender más bien al paso de las premisas a la conclusión de (2), puesto que la mayoría de los lectores habrán notado que esta misma es una inferencia inductiva precisamente de la clase cuya fiabilidad estamos en este momento preocupados por investigar.

Pero, ¿hay algo incorrecto en esto? No es que la discusión hasta el momento haya identificado algún defecto en la 
inducción, de una clase que implicaría que debiera ser eliminada de la batería de procedimientos por los que normalmente llegamos a nuestras creencias. En particular, hemos acordado que la invalidez lógica de las inferencias inductivas por sí sola no pone en descrédito a la inducción. Dado esto, cuando surge cierta cuestión de hecho —a saber, ¿son las inferencias inductivas siempre fiables?-, ¿qué es más natural que intentar resolver esta cuestión por medio de nuestros procedimientos normales de investigación que incluyen, de hecho, a nuestros procedimientos inductivos?

Sé que para algunas sensibilidades filosóficas esto parecerá excesivamente complaciente: seguramente no tenemos derecho a ningún método de investigación hasta que hayamos demostrado su valor. Pero, ¿dónde se supone que comencemos? Ciertamente necesitamos comenzar con algunos métodos de pensamiento, para no caer en la catatonia filosófica. Muchos filósofos, me doy cuenta, querrán seguir a Descartes y restringir nuestros métodos iniciales a la introspección y a la intuición. Pero la razón de Descartes para esta restricción era que prometía certeza, y ya hemos acordado que este era un desideratum innecesario para nuestros métodos de pensamiento. Parecería igualmente razonable continuar con nuestros métodos normales de pensamiento, al menos hasta que descubramos alguna razón para desconfiar de ellos. Y estos métodos incluirán la inducción puesto que, para repetirlo, aún no se nos ha dado ninguna razón para desconfiar de la inducción. 


\section{Variedades de circularidad}

Aun así, y si todavía no se ha mostrado nada erróneo con la inducción en general, bien puede parecer que hay algo errado en particular con el argumento inductivo (2). Pues ¿no es acaso (2) un argumento circular y, por ende, ilegítimo? Esta objeción requiere ser tratada cuidadosamente. Es verdad, como veremos en breve, que una circularidad de cierto tipo está presente en (2). No obstante, a condición de que mantengamos en mente con firmeza la tarea argumentativa a la que (2) se dirige, veremos también que esta circularidad no es condenatoria.

Como primer paso, necesitamos distinguir entre «circularidad de premisas» $\mathrm{y}$ «circularidad de reglas» (ver Braithwaite, 1953: 276-7; Van Cleve, 1984: 558). Un argumento es circular de premisa si su conclusión está contenida entre sus premisas. Un argumento es circular de regla si llega a la conclusión de que una cierta regla de inferencia es fiable al usar exactamente esa misma regla de inferencia. Claramente la circularidad de premisas es un vicio en un argumento. El punto de un argumento es llevarnos de viejas creencias, que son aceptadas como premisas, a alguna nueva creencia como su conclusión. Pero si la conclusión ya está contenida en las premisas, entonces el argumento fallará en su tarea primaria. No obstante, el argumento (2) claramente no es circular de premisa. Es un argumento genuinamente expansivo, cuya conclusión (que todas las inducciones producen conclusiones verdaderas), manifiestamente deja atrás sus premisas (que $\mathrm{N}$ inducciones hasta el momento han producido verdades $)^{12}$.

\footnotetext{
${ }^{12}$ Hay un problema con la noción de circularidad de premisa: si «contenido entre las premisas» sólo significa implicación lógica, entonces todos los argumentos deductivos serán circular de premisa.
} 
Por otra parte, el argumento (2) es circular de regla. Incluso si la afirmación de que la inducción es fiable no aparece entre sus premisas, hace uso de una inferencia inductiva para llegar a la conclusión de que la inducción es fiable. Tengo varios comentarios respecto a la circularidad de regla de (2), pero primero haré un comentario más amplio, no sobre el argumento (2) en particular, sino acerca de la circularidad de regla como tal, a saber, que difícilmente puede ser un requisito general, sobre todas las formas legítimas de inferencia, que sea posible mostrar de alguna manera no circular que todas ellas son confiables. Tal cosa descalificaría incluso a la deducción como una forma legítima de inferencia. (Mientras que es posible demostrar que las inferencias deductivas son fiables —en efecto, que son necesariamente fiables- por medio de las pruebas semánticas estándar de validez, estas mismas demostraciones emplean incuestionablemente la deducción). De modo que el hecho de que la inducción sólo pueda mostrarse fiable mediante un argumento circular de regla, como en (2), ciertamente no es en sí mismo una razón inmediata para desconfiar de la inducción.

Pero esto es meramente repetir el punto de que aún no se nos ha dado un buen argumento para desconfiar de la inducción. Nuestra preocupación actual, no obstante, es la de si (2) nos lleva más allá de esto y nos proporciona una base positiva para confiar en la inducción, a pesar del hecho de que se admite que es circular de regla ${ }^{13}$. Recordemos el contexto

\footnotetext{
Algunos filósofos, notablemente Descartes y Mill, consideraron que esto mostraba que la deducción no es informativa. La mayoría pretende entender «contener» de manera más estricta. Sin embargo, este debate carece de relevancia para nuestras preocupaciones actuales, ya que todos admitirán que el argumento no-deductivo (2) no es premisa circular.

${ }^{13} \mathrm{Si}$ lo hace, entonces esto responderá a la segunda de las preguntas planteadas al inicio de esta sección acerca de las premisas de (2), a saber, la pregunta acerca de cómo sabemos que las conclusiones («Todos los As son Bs») de inducciones pasadas son verdaderas. La respuesta es: por inducción.
} 
del argumento en el que aparecía (2). Acordamos, sobre bases fiabilistas generales, que la inducción no necesita ser lógicamente válida para producir conocimiento, sino que produciría conocimiento sólo en caso de que sea fiable. No obstante, el escéptico señaló que no podemos simplemente dar por sentado que la inducción es fiable. A lo que respondimos que no estamos dando esto por sentado, sino que tenemos un buen argumento, basado en evidencia empírica, para la conclusión de que la inducción es fiable, a saber, el argumento (2). Me parece que en este contexto específico, el contexto de mostrarle a un escéptico que acepta el fiabilismo que no sólo nos estamos facilitando la creencia de que la inducción es fiable, (2) hace precisamente el trabajo que se requiere que haga.

\section{¿Quién necesita persuasión?}

Quizá la mejor manera de mostrar esto es detallar algunas de las tareas que el argumento (2) no pretende cumplir. Para empezar, debería reconocerse que el argumento (2) no sería adecuado para persuadir a personas que no hacen inducciones de que empiecen a hacerlas. Mientras la conclusión de (2) (que las inducciones son fiables), sería ciertamente una buena razón para que tales personas empezaran a inducir si la aceptaran, claramente no estarían persuadidas de hacerlo debido a (2), puesto que la ruta de las premisas de (2) a su conclusión requiere precisamente la clase de inferencia inductiva que estas personas evitan. En particular, entonces, (2) no será

Puesto que, si la distinción entre la circularidad de reglas y la de premisas legitima el movimiento inductivo de las premisas de (2) a la conclusión de (2), entonces también servirá para legitimar los movimientos inductivos antecedentes de casos de As que son Bs a «Todos los As son Bs» (ver Van Cleve, 1984: 560-1). 
adecuado para persuadir a personas que ya han reflexionado sobre la fiabilidad de la inducción y han sido persuadidas, por cualesquiera razones, de que deberían dejar de llevar a cabo inducciones, de que deberían volver a empezar.

No obstante, en el presente contexto del argumento, esto no demerita el valor de (2). El argumento (2) no está dirigido a personas que evitan las inducciones. Podemos todavía descubrir buenas razones para evitar las inducciones, y en efecto en las siguientes secciones examinaré algunas razones posibles, pero por ahora estamos asumiendo que aún no se ha mostrado nada erróneo con la inducción y consideramos si, dado esto, el argumento (2) puede mostrarnos si la inducción es fiable. De modo que (2) debería ser pensado como dirigiéndose a personas a las que aún no se les da ninguna razón para desconfiar de la inducción. Y (2) debería seguramente persuadir a tales personas al menos de su conclusión.

Me doy cuenta de que muchos lectores pensarán que, si (2) es un buen argumento en defensa de la inducción, entonces debería ser capaz de persuadir a cualquier criatura inteligente con cualesquiera hábitos epistemológicos. Pero ésta es una exigencia extremadamente fuerte y no es en absoluto claro por qué habríamos de aceptarla. La única razón posible, una vez más, parece provenir de la suposición de que el conocimiento requiere certeza, junto con la suposición de que sólo las clases de procesos formadores de creencias que pueden plausiblemente producir certeza son operaciones conscientes cuya infalibilidad lógica está disponible introspectivamente. En conjunto estas suposiciones implican que cualquier fuente de conocimiento debería en principio ser reconocible como tal por cualquier criatura consciente, en virtud de sus habilidades introspectivas y, por ende, estas suposiciones implican que un buen argumento a favor 
de la legitimidad de alguna fuente de conocimiento debería persuadir a cualquier persona, sin importar cuán testaruda sea su actitud en el error. No obstante, una vez que rechazamos la suposición de que el conocimiento requiere certeza, esta línea entera de razonamiento se desmorona y la fuerte exigencia de que una buena defensa de la inducción debe persuadir a cualquier criatura consciente no encuentra manera de respaldarse.

Estas últimas observaciones se relacionan con la cuestión de los argumentos «contrainductivos» a favor de la «contrainducción». Se ha observado con frecuencia que los argumentos inductivos a favor de la inducción, como (2), tienen imágenes reflejas contrainductivas. Los contrainductivistas, cuando observan que una cantidad de As son todas Bs, concluyen que el próximo A no será un B. Cuando se les señala que esto es ilógico, ellos pueden responder: «¿Y qué? Por ilógico que pueda ser, esto no muestra que no es de hecho una buena forma de llegar fiablemente a conclusiones verdaderas». Y nosotros decimos: «De acuerdo. Pero, ¿qué bases tienes para suponer que las contrainducciones de hecho producen conclusiones verdaderas?». Ellos responden: «iAh, eso es lo que te preocupa! Veamos la evidencia en relación con la cuestión. En gran cantidad de ocasiones en el pasado las personas han contrainducido y han sido llevadas a conclusiones falsas. De modo que concluimos - contrainductivamente- que la próxima vez que contrainduzcamos obtendremos una conclusión verdadera». Hay lugar para discutir si ésta es en efecto una imagen reflejo perfecta de (2) (ver Van Cleve, 1984: n. 16). Pero dejémoslo pasar. El punto más importante es que incluso si los contrainductivistas logran reflejar (2), esto no hace nada por desacreditar en sí mismo a (2). Ya he concedido que (2) no persuadirá a las personas 
que no hacen inducciones para que empiecen a hacerlas. El contrainductivismo ahora simplemente nos da un ejemplo adicional de personas que tienen disposiciones inferenciales anormales, y que no serán, por ende, persuadidas por (2). A excepción de esto, la parábola del contrainductivista añade un giro adicional, a saber, que los contrainductivistas serán persuadidos, por su reflejo de (2), de la conclusión de que sus disposiciones contrainductivas anormales son fiables. Pero todo esto deja a (2) intacto, no deberíamos esperar que realice la tarea imposible de sacar a no-inductivistas imaginarios de su no-inductivismo — su tarea es sólo permitirle a la gente normal, como nosotros, resolver el tema de si la inducción es fiable.

A estas alturas, algunos lectores podrían estar sintiendo que el argumento (2) no hace gran cosa. En efecto, si sólo funciona para personas que ya realizan inducciones, ¿hace realmente algo? Mi respuesta es que no se supone que haga gran cosa. Casi todo el trabajo serio estaba concluido antes de que (2) apareciera en escena. De manera más importante, los argumentos a favor del fiabilismo ya han mostrado que la invalidez lógica de la inducción no es un problema. El argumento (2) sólo pretende mostrar que, dado que no hay nada problemático acerca de la inducción, entonces no hay obstáculo para que concluyamos que es fiable y que, por ende, produce conocimiento.

Los filósofos entrenados esperarán naturalmente que una «justificación de la inducción» haga algo por rehabilitar la inducción, en respuesta a un argumento de que hay algo erróneo en ella. Pero (2) no pretende ser una «justificación» en este sentido, de modo que no deberíamos condenar esto como una falla. 


\section{La estrategia generalizada}

Seamos más realistas acerca de la inducción como primer paso hacia la generalización de la estrategia antiescéptica esbozada en las secciones anteriores. Ya he mencionado una forma en la que la discusión precedente acerca de la inducción ha involucrado una idealización, a saber, con respecto a la suposición de que en nuestra experiencia todas las inducciones enumerativas pasadas han sido exitosas. Esta suposición es, por supuesto, manifiestamente falsa. Hay muchos buenos ejemplos de inducciones enumerativas que llevan a conclusiones falsas, desde el pollo de Russell, que esperaba ser alimentado todos los días, hasta el físico newtoniano que esperaba que la aceleración siempre fuese inversamente proporcional a la masa en reposo.

En cualquier caso, al margen de tal evidencia directa, hay también un argumento de principio para mostrar que la inducción enumerativa simple no puede ser un método confiable de inferencia. Me refiero al «nuevo problema de la inducción» de Goodman. Goodman (1954) muestra que hay muchísimas formas de clasificar sucesos, muchísimas As y Bs para que cada ejemplar del esquema (1) produzca una conclusión verdadera. En efecto, Goodman muestra cómo construir, para cada ejemplar de (1) que pueda producir una conclusión verdadera, una infinidad de otros ejemplares que entonces producirán conclusiones falsas.

Estos son buenos argumentos en contra de la inducción enumerativa. Es importante reconocer, no obstante, que son bastante independientes de la objeción tradicional a la inducción. No simplemente señalan que la inducción enumerativa es lógicamente inválida. Por el contrario, muestran que la in- 
ducción enumerativa no sólo es inválida, sino abiertamente no fiable.

La moraleja es, para nosotros los fiabilistas que queremos oponernos al escepticismo acerca de la inducción, que haríamos mejor en no aferrarnos a la inducción enumerativa simple tal como está esquematizada en (1). Más bien, necesitamos mostrar de alguna manera que nuestras prácticas inductivas efectivas tienen una estructura más sofisticada, que quizá involucra restricciones sobre las As y Bs que son candidatos para la proyección, y quizá está limitada en los grados de creencia que extendemos a sus conclusiones.

Diré un poco más acerca de tal modelo alternativo de la inferencia inductiva dentro de poco. Pero primero hay que observar que tal modelo abrirá una vez más un camino a la estrategia antiescéptica esbozada arriba. Imaginemos que podemos mostrar que nuestras prácticas inductivas efectivas son más sofisticadas que la inducción enumerativa simple, y que, por tanto, éstas no pueden ser desacreditadas como no fiables por el nuevo problema de Goodman ni por su desempeño pasado. E imaginemos, además, que cuando investigamos la fiabilidad de nuestros métodos inductivos, usando los métodos de investigación existentes, nos encontramos siendo capaces de concluir que es fiable. Entonces esto rechaza el escepticismo acerca de nuestra práctica inductiva. Como antes, ni el hecho de que esta práctica sea inválida ni el hecho de que su fiabilidad pueda sólo ser descubierta a manera circular de regla, será una barrera para nuestra conclusión de que aporta conocimiento.

En este capítulo me he concentrado en la inducción. Pero la estrategia antiescéptica que he usado puede ser generalizada para aplicarse a nuestros métodos de formación de creencias en general, incluyendo métodos no inferenciales 
como la percepción y la memoria. Si la única objeción a ellos es que no proporcionan certeza, en el sentido de que es posible que produzcan creencias falsas, entonces ésta no es una razón para creer que no son fiables. Y si, además, la investigación muestra que esos métodos son fiables, entonces cualquier circularidad de regla a pesar de todo estará en posición de concluir que aportan conocimiento ${ }^{14}$.

\section{Inducción no enumerativa}

Ahora quiero esbozar un modelo más realista de la inducción, con la intención de mostrar que la inducción no está de hecho desacreditada como no fiable ni por el argumento de Goodman ni por su desempeño pasado.

Para comenzar con Goodman, nótese que cualquier solución al problema de Goodman probablemente nos conducirá a ver la inducción en términos de eliminación más que de enumeración, pues cualquier solución involucrará alguna limitación sobre las As que son candidatos posibles para ser asociadas con alguna B específica. Pero si tenemos tal rango limitado de posibles As, entonces debería ser posible que encontremos datos experimentales que identifiquen al antecedente efectivo de $\mathrm{B}$ al eliminar a los otros candidatos, más que al proporcionar ejemplares repetidos de la generalización relevante.

Dentro del contexto de suposiciones deterministas, los métodos de la inducción de J. S. Mill muestran qué clases de datos son requeridos para alcanzar tales conclusiones elimi-

\footnotetext{
${ }^{14}$ Uno de los objetivos de mi Reality and Representation (1987) era mostrar cómo podríamos investigar todos nuestros métodos estándar de formación de creencias, tal como podríamos investigar cualquier otro fenómeno natural, y descubrir que aquellos métodos son, por lo general, fuentes fiables de verdad.
} 
nativas, dadas varias clases de suposiciones acerca de rangos limitados de posibles antecedentes. Mucha de la ciencia contemporánea, es cierto, no asume el determinismo. Pero hay análogos probabilistas de los métodos de Mill que usan técnicas de análisis de varianza y regresión múltiple para discriminar, entre los factores que podrían en principio ser correlacionados con algún efecto $\mathrm{B}$, aquellos que están correlacionados con él de manera genuina más que espuria ${ }^{15}$.

Los métodos de Mill y otros afines son poco discutidos en nuestros días por los filósofos. Esto es desafortunado, pues los métodos de Mill están claramente mucho más de acuerdo con la práctica científica actual que el modelo filosófico estándar de la inducción por enumeración de ejemplares. La ciencia no necesita un gran número de observaciones repetidas para establecer que el cobre se derrite a $1,084^{\circ} \mathrm{C}$, o que la varicela es causada por un virus de herpes, o que el agua es $\mathrm{H}_{2} \mathrm{O}$. Más bien, puesto que sólo hay tantos puntos de fusión posibles, o agentes infecciosos, o combinaciones de elementos, unas cuantas observaciones simples serán suficientes en cada uno de tales casos para discriminar la ley actual de entre las posibles alternativas iniciales.

No hay duda de que parte de la razón por la que los filósofos se han interesado poco en los métodos de Mill es que no ofrece ninguna respuesta satisfactoria a las dudas escépticas acerca de la inducción. Pero el argumento de este capítulo muestra cómo podemos defender los métodos de Mill en contra de las dudas escépticas, a saber, mostrando que esos

\footnotetext{
${ }^{15}$ Estos análogos probabilistas de los métodos de Mill involucran dos pasos inferenciales: primero, de los datos muestra a las correlaciones objetivas; luego, de estas correlaciones a las causas. Mientras este segundo paso puede ser cien por ciento fiable, el primero no puede evitar las incertidumbres de la inferencia estadística (ver Papineau; 1993). Tengo esperanzas en una explicación de tipo fiabilista de la inferencia estadística, pero no entraré en los detalles aquí.
} 
métodos son una fuente fiable de creencias verdaderas, y por ende de conocimiento. Además, el argumento de este capítulo muestra que no hay razón por la cual tal demostración no tenga que ser de regla circular: lo que queremos es alguna ruta hacia la conclusión de que esos métodos son fiables, pero no necesariamente una ruta que evite esos mismos métodos.

En lo que resta de esta sección bosquejo una posible ruta hacia la conclusión de que los métodos millianos de inducción eliminativa son fiables ${ }^{16}$. Pero antes de hacerlo, permítaseme observar que una demostración de la fiabilidad de los métodos de Mill constituirá también una respuesta implícita al nuevo problema de la inducción de Goodman, ya que, para que los métodos de Mill sean fiables, sólo cierto rango limitado de As puede asociarse con cualquier B específico. De modo que cualquier demostración de la fiabilidad de los métodos de Mill requerirá mostrar que tales As son en efecto los únicos candidatos para proyectarse junto a B. Esto es, si los métodos de Mill funcionan, entonces debe haber razones generales por las que sólo algunos tipos de generalizaciones —como «Todas las esmeraldas son verdes»— están disponibles, y por las que otras — Todas las esmeraldas son verzules»- no lo están. Una demostración de la fiabilidad de los métodos de Mill mostrará así por qué verde es proyectable respecto de las esmeraldas y verzul no lo es.

Veamos un poco más de cerca los métodos de Mill. Es importante, al pensar acerca de la fiabilidad de estos métodos, no considerar a la clase de suposiciones de fondo que nos dicen, por ejemplo, que $B$ tiene un antecedente determinista, y que $\mathrm{A}_{1}, \ldots, \mathrm{A}_{\mathrm{n}}$ son las únicas posibilidades, como una premisa para una inferencia inductiva milliana a la que

${ }^{16}$ Esto ampliará la discusión en Papineau (1987; 196-8). 
añadimos las otras premisas observacionales de que $A_{1}, \ldots$, $A_{n-1}$ han sido encontradas $\sin B$, para concluir que $A_{n}$ es el antecedente actual, ${ }_{17}^{17}$ pues esto sólo haría a la inducción milliana un caso especial de deducción, y además dejaría a los científicos que realizan inferencias millianas con una premisa no liberada, a saber, la premisa de que una de entre $A_{1}, \ldots$, $A_{n}$ es el antecedente determinista de $B$.

Más bien, deberíamos pensar en la observación de $\mathrm{A}_{1^{\prime}}$ ..., $A_{n-1} \sin B$ como la única premisa para una inferencia inductiva milliana. No necesitamos suponer que los mismos científicos saben por qué esta inferencia funciona (aunque probablemente lo sabrán), lo único que importa, en primer lugar, es que estén dispuestos, al observar $A_{1}, \ldots, A_{n-1} \sin B$, a concluir que $A_{n}$ es el antecedente actual.

La siguiente tesis de que $B$ tiene un antecedente determinista, y de que $\mathrm{A}_{1}, \ldots, \mathrm{A}_{\mathrm{n}}$ son las únicas posibilidades, sólo es requerida al nivel metafilosófico, cuando abordamos la cuestión de la fiabilidad de la inferencia inductiva milliana. Somos nosotros, los filósofos, quienes queremos averiguar si la inferencia milliana es fiable, quienes requerimos saber que una de entre $A_{1}, \ldots, A_{n}$ debe ser el antecedente determinista de $B$, no los científicos que de hecho hacen esta inferencia.

De modo que los científicos que realizan inferencias millianas no son necesariamente culpables de servirse de premisas no liberadas. La única premisa que ellos requieren es la de que $A_{1}, \ldots, A_{n}$ han sido encontrados $\sin B, y$ pueden obtenerla por medio de la observación. Por otra parte, la exigencia de premisas no liberadas puede ser razonablemente nivelada por un filósofo que — como yo mismo- explícita-

\footnotetext{
${ }^{17}$ Este simple método de las diferencias es sólo uno de los métodos de Mill. Para un catálogo completo ver el Apéndice de Mackie (1974).
} 
mente argumenta que tales inferencias inductivas millianas son fiables, sobre la base de que una de entre $A_{1}, \ldots, A_{n}$ debe ser el antecedente determinista de B. Por lo que debo entonces, cuando menos, ofrecer alguna explicación de mis bases para esta última afirmación.

Cuando aún pensábamos acerca de la inducción como enumeración simple, éste era el punto en el que volvíamos a la inducción sobre sí misma, y usábamos una inferencia inductiva para llegar a la conclusión de que la inducción es fiable. Si pudiéramos hacer lo mismo en el contexto presente, entonces una vez más tendríamos una respuesta a las preguntas escépticas acerca de la inducción. No obstante, no es tan obvio que podamos hacer el mismo movimiento dentro del contexto de la aproximación eliminativa a la inducción.

Considérese la inferencia por la que los investigadores médicos establecen que la varicela es causada por un virus de herpes. Podemos interpretar a los investigadores como infiriendo esto a partir de un conjunto de observaciones del tipo de Mill acerca de la presencia y ausencia de varios virus en personas con y sin varicela. Y podemos explicar la fiabilidad de esta inferencia sobre la base de que los agentes virales son las únicas posibles causas de enfermedades infecciosas que no responden a antibióticos.

Pero, ¿qué pasa ahora con esta última afirmación de que los virus son la única posible causa de enfermedades infecciosas resistentes a antibióticos? Necesitamos esta afirmación para explicar la fiabilidad de la inferencia milliana de los investigadores médicos. Pero, ¿de dónde proviene? El problema es que no podemos obtenerla de la misma inferencia milliana en cuestión, pues esta forma de inferencia sólo puede decirnos qué virus son causa de qué infecciones resistentes a antibióticos, no qué agentes son responsables de las infeccio- 
nes resistentes a antibióticos en general. Esto es, la inferencia milliana en cuestión no está ella misma autorrespaldada en la manera en que lo está la inducción enumerativa.

Quizá aún podamos establecer la afirmación general de que los virus siempre causan enfermedades infecciosas resistentes a antibióticos por otro tipo de inducción eliminativa diferente de la primera. Lo que necesitaríamos sería una que use observaciones adecuadas para eliminar todos los otros posibles agentes además de los virus como causas de tales enfermedades, no una que elimine a todos los otros virus además del herpes como causa de la varicela.

Ahora bien, es suficientemente plausible que haya un modo fiable tal de inducción eliminativa. Pero entonces el mismo problema surge de nueva cuenta. Pues la fiabilidad de este nuevo modo de inducción eliminativa descansará ahora en algún hecho adicional, como el de que sólo cierto rango de agentes físicos invasivos que alteran la bioquímica de los pacientes son posibles candidatos a causas de enfermedades. Y así el filósofo que quiera afirmar la fiabilidad de esta nueva forma de inducción eliminativa tiene una nueva premisa no liberada con la cual ingeniárselas.

Una clase de retroceso amenaza. Las inducciones eliminativas parecen caer naturalmente en una jerarquía, con la fiabilidad de cada una siendo explicable sólo con ayuda de suposiciones que se derivan de una forma de inferencia superior en la jerarquía. Podemos explicar la fiabilidad de los procedimientos que muestran que el virus del herpes causa la varicela invocando la suposición de que las enfermedades infecciosas resistentes a antibióticos son siempre debidas a virus. Pero esta suposición, en cambio, necesita ser establecida por un procedimiento diferente, cuya fiabilidad depende de alguna suposición como la de que todas las enfermedades se deben a agentes 
físicos invasivos que alteran la bioquímica de los pacientes. $\mathrm{Y}$ quizá esta suposición también pueda ser establecida por una inducción eliminativa que use observaciones relevantes para discriminar entre esta suposición y otros modelos físicamente posibles de enfermedad. Pero esto nos deja a los filósofos con la tarea de explicar cómo llegamos a la suposición de que las posibilidades físicas son las únicas posibilidades.

Podemos esperar encontrar esta clase de jerarquía repetida en diferentes áreas de la ciencia. Quizá el hecho de que tales secuencias se conducirán característicamente a partir de suposiciones específicas de la materia a suposiciones generales acerca de la posibilidad física ofrece una manera de salir del problema. Si el regreso ha de parar en algún punto necesitaremos encontrar una forma de inducción eliminativa que pueda establecer su propia fiabilidad, como lo hizo antes la inducción enumerativa. Me gustaría sugerir tentativamente que tal forma de inducción eliminativa podría ser encontrada al nivel de la ciencia física básica. En este nivel la tarea es descubrir los límites de la posibilidad física misma. La física básica intenta decidir entre distintas teorías de la fuerza, la materia y el espacio-tiempo, entre diferentes teorías de qué es físicamente posible. Ahora bien, es plausible que en este nivel la estrategia inductiva usada por los físicos sea ignorar cualesquiera teorías que carezcan de cierta clase de simplicidad física. Si esto es correcto, entonces esta estrategia inductiva, cuando se aplica a la cuestión de la constitución general del universo, conducirá inevitablemente a la conclusión de que el universo está compuesto de constituyentes que ejemplifican la clase relevante de simplicidad física. Y entonces, una vez que hemos alcanzado esta conclusión, podemos usarla para explicar por qué esta estrategia inductiva es fiable. Puesto que si los constituyentes del mundo son en 
efecto caracterizados por la clase relevante de simplicidad física, entonces una metodología que utilice observaciones para decidir entre alternativas con esta clase de simplicidad será por esa razón una ruta fiable a la verdad.

Debería enfatizarse que esta historia no depende de ninguna noción a priori de simplicidad. En esta medida el término «simplicidad» es quizá un nombre inapropiado. La explicación simplemente depende de la existencia de ciertos rasgos generales que caracterizan las respuestas verdaderas a cuestiones de la teoría física fundamental. Lejos de ser cognoscibles a priori, estos rasgos bien pueden ser contraintuitivos para quien no está entrenado científicamente. Así, el movimiento circular no es especialmente «simple», en el sentido relevante, comparado con las clases de movimiento que resultan de las leyes del inverso del cuadrado de la fuerza. La discontinuidad no es «simple», a pesar de que la experiencia cotidiana nos muestra fronteras claras entre los objetos físicos y sus alrededores. Las explicaciones en términos de causas observables no son «simples», comparadas con la explicación por medio de mecanismos microscópicos ocultos.

\section{La contingencia histórica del conocimiento}

Se sigue de esta última observación que los métodos de inferencia que nos permiten hacer descubrimientos acerca del mundo físico no son innatos al pensamiento humano. En algún punto en la historia humana la gente adquirió la habilidad, que antes no tenía, de enfocarse específicamente en ciertas clases de explicaciones de los fenómenos físicos, e ignorar otras. 
Podría parecer que esto da lugar a un problema para mi respuesta global al escepticismo. Mi sugerencia ha sido que deberíamos revisar nuestros métodos existentes de pensamiento para confirmar que son fuentes fiables de creencia verdadera $y$, por ende, de conocimiento. $Y$, en respuesta a la objeción de que estas revisiones emplean aquellos mismos métodos existentes de pensamiento, he observado que aun así no se nos ha dado ninguna razón para desconfiar de esos métodos.

No obstante, algunos lectores pueden sentir que esta estrategia es marcadamente menos plausible cuando se aplica a los métodos de pensamiento que son históricamente casualidades, más que a aquellos que son una parte innata de la dotación cognitiva humana. Las demostraciones de fiabilidad que dependen de tales métodos innatos de pensamiento al menos tienen la virtud de persuadir a todos los seres humanos actuales. Son sólo los individuos de pensamiento puramente experimental, como los contrainductivistas, los que no serán persuadidos por tales demostraciones de la existencia del conocimiento humano. Pero las demostraciones de la fiabilidad que apelan a métodos de pensamiento históricamente contingentes como la preferencia de hipótesis «físicamente simples», fallarán en su intento de persuadir a muchos seres humanos actuales también - a saber, a todos aquellos individuos en la distancia histórica, geográfica o cultural que no han adoptado los métodos de pensamiento contingentes en cuestión. Aun así, ¿acaso importa? Que otra gente reniegue de algún método de pensamiento no es en sí mismo una razón conclusiva para desconfiar de ese método de pensamiento, ni, por tanto, para desconfiar de las vindicaciones del conocimiento humano que dependen de él. Quizá nuestras razones para pensar que tenemos conocimiento, y que el escéptico está por tanto equivocado, no lograrán per- 
suadir a varios seres humanos actuales, así como a los imaginarios contrainductivistas. Pero esto apenas muestra que no son buenas razones. Después de todo, hay gran cantidad de evidencia para mostrar que muchos métodos de pensamiento que son innatos al pensamiento humano no merecen confianza, y que por ende haríamos mejor en reemplazar estos hábitos innatos por alternativas históricamente contingentes.

Quizá una clase de generalización a partir de la variabilidad yace tras el difundido sentimiento de que los métodos de pensamiento históricamente contingentes son epistemológicamente sospechosos. Tengo en mente el siguiente argumento: diferentes personas en tiempos y lugares distintos han adoptado muchos procedimientos diferentes para decidir cuestiones acerca de, digamos, las causas de los fenómenos observables. Puesto que estos distintos procedimientos por lo común proporcionan respuestas mutuamente inconsistentes, sólo una de las cuales puede ser verdadera, la mayoría de estos procedimientos deben ser no fiables. En particular, por tanto, es muy probable que nuestro procedimiento preferido en la actualidad sea no confiable.

No obstante, una vez escrita, la debilidad de esta línea de argumentación es evidente. Pues presupone que un conjunto tal de procedimientos que varían históricamente forma una categoría homogénea, cuyas inadecuaciones totales, por ende, restan valor por igual a todos los miembros de la categoría. Sin embargo, bien podría haber diferencias relevantes entre los miembros de la categoría, diferencias que bloquearían la inferencia a partir de «la mayoría de los procedimientos en el grupo no son fiables», a «este procedimiento en particular probablemente no es fiable». Por ejemplo, podría ser que algún procedimiento actualmente preferido haya sido adoptado como resultado de reflexión crítica, más que como 
mera defensa de la tradición; quizá hace uso del experimento controlado, más que de meras habladurías; quizá involucra precisión matemática, más que meras conjeturas. Estos rasgos no proporcionan, por supuesto, una demostración concluyente de que el procedimiento en cuestión sea una fuente confiable de verdad, pero son seguramente suficientes para invalidar el argumento de que, puesto que varios procedimientos que carecen de estos rasgos no son fiables, nuestro procedimiento preferido tampoco será fiable ${ }^{18}$.

\section{La metainducción pesimista}

El argumento a partir del relativismo considerado en la última sección debe ser distinguido de la bien conocida «metainducción pesimista a partir de la falsedad pasada». La «metainducción pesimista» también trae a cuento la fiabilidad de las estrategias inductivas de la ciencia moderna. Pero en vez de mantener que no hay nada que escoger de entre estas estrategias y las alternativas incompatibles que han sido practicadas por humanos histórica y culturalmente distantes, la metainducción pesimista se enfoca directamente en los productos del método científico moderno, y argumenta de inmediato que ese método científico debe no ser fiable, puesto que característicamente desemboca en creencias falsas.

\footnotetext{
${ }^{18}$ En Reality and Representation mi respuesta al argumento a partir de la variabilidad era que no había variabilidad entre baterías autocertificadoras de procedimientos de formación de creencias, esto es, baterías de procedimientos que generan conclusiones acerca de su propia fiabilidad (1987, cap. 10). Aún creo que este argumento puede funcionar, pero ahora me parece un martillo demasiado grande para romper una nuez tan pequeña. Desde mi perspectiva actual, la autocertificación es meramente un ejemplo de la clase de diferencias relevantes que pueden bloquear la generalización a partir de la variabilidad.
} 
Después de todo - pueden señalar los pesimistas- ahora consideramos que la física newtoniana, la teoría flogistista de la combustión, la teoría de que los átomos son indivisibles, y así sucesivamente, son todas falsas. De modo que, ¿no se sigue inmediatamente que el método por el cual fueron obtenidas estas teorías no puede ser una ruta fiable a la verdad $?^{19}$

Esta metainducción pesimista es incuestionablemente un argumento importante, que indica que la precaución es necesaria en la teorización científica. No obstante, da lugar a muchas preguntas de detalle, y tratarla aquí de manera completa extendería nuestra discusión excesivamente. Me limitaré a algunos breves comentarios, que espero bastarán para mostrar que, incluso si la metainducción pesimista recomienda precaución, esto no significa que debamos suspender por completo el juicio sobre todas las afirmaciones científicas.

El defecto básico en la metainducción pesimista es un reflejo del que encontramos en el argumento a partir de la variabilidad discutido en la última sección: agrupa dentro de una categoría homogénea elementos que merecen un tratamiento por separado. El argumento a partir de la variabilidad agrupa todos los procesos de pensamiento humano. De manera similar, la metainducción pesimista agrupa todas las teorías científicas.

Al hacerlo, la metainducción pesimista ignora diferencias importantes entre teorías científicas, diferencias relevantes para la cuestión de si los antecedentes históricos producen dudas sobre su verdad. Para empezar, la tendencia a la falsedad teórica es mucho más común en algunas

\footnotetext{
${ }^{19}$ ¿Acaso no se destruye a sí mismo este argumento, al arrojar duda sobre las teorías científicas de nuestros días, cuya verdad asume cuando juzga que las teorías pasadas son falsas? Pero el argumento puede ser presentado como una reductio: si las teorías actuales son verdaderas, entonces las teorías pasadas son falsas, de modo que, por metainducción pesimista, las teorías actuales son falsas, por lo que las teorías actuales son falsas (ver Jardine, 1986).
} 
áreas de la ciencia que en otras. Así, es relativamente normal que las teorías sean derrocadas en cosmología, digamos, en física de partículas fundamentales, o en el estudio de la evolución de los primates. En contraste, las teorías de la composición molecular de distintos compuestos químicos (tales como que el agua está constituida por hidrógeno y oxígeno), o las causas de enfermedades infecciosas (la varicela es causada por el virus del herpes), o de la naturaleza de los fenómenos físicos ordinarios (el calor es movimiento molecular), son característicamente retenidas una vez que han sido aceptadas. De modo que el testimonio de la forma pasada cuenta en contra de algunas clases de teorías más que de otras. Las fallas científicas pasadas indican precaución acerca de la tesis de que los quarks y los leptones son los bloques últimos de construcción de la materia. Pero no nos dan razón para dudar de que el agua esté constituida por hidrógeno y oxígeno.

Tampoco necesitamos considerar esta tasa diferencial de éxito de diferentes clases de teorías como un dato histórico inexplicable. Puede ser simplemente el resultado de que la evidencia necesaria fuese más fácilmente accesible en algunas áreas que en otras. Los paleoantropólogos quieren saber cómo muchas especies de homínidos estuvieron presentes en la Tierra hace tres millones de años. Pero su evidencia consiste en unas cuantas piezas de dientes y huesos. De modo que es apenas sorprendente que el descubrimiento de nuevos sitios fósiles a menudo los llevará a cambiar sus puntos de vista. El mismo punto se aplica a escala mayor en cosmología y física de partículas. Los científicos en estas áreas quieren responder preguntas muy generales acerca de lo muy pequeño y lo muy distante. Pero su evidencia se deriva del limitado rango de instrumentos tecnológicos que han 
inventando para investigar estos dominios. Así que, una vez más, apenas sorprende que sus teorías hayan de permanecer al nivel de hipótesis tentativas. En contraste, en aquellas áreas en las que la evidencia adecuada está disponible, tales como la química y la medicina, no hay una barrera correspondiente para que la ciencia se mueva de hipótesis tentativas a conclusiones firmes.

No quiero sugerir necesariamente que haya un nivel de evidencia que asegurará inferencias inductivas de acierto seguro, inferencias que sean cien por ciento fiables en el mundo actual. Quizá incluso la mejor evidencia obtenible llevará en ocasiones a los científicos a extraviarse. Sin embargo, al distinguir entre teorías bien respaldadas y mal respaldadas, podemos por lo menos evitar que se desmoronen todas las conclusiones científicas con las fallas de especulaciones pobremente respaldadas.

Si incluso la mejor evidencia es menos que acierto seguro, entonces estrictamente no deberíamos concederle nunca creencia completa a las conclusiones científicas. Más bien, deberíamos adaptar nuestro grado de creencia a la fiabilidad de conclusiones similarmente evidenciadas, en la forma indicada en la sección 6. Pero mientras la tasa de éxito de inferencias bien evidenciadas sea alta, este grado de creencia puede aun ser cercano a uno. Las especulaciones basadas en evidencias precarias pueden a menudo resultar falsas. Pero ésta no es razón para pensar que todas las conclusiones inductivas sufrirán el mismo destino. 


\section{BIBLIOGRAFÍA}

Braithwaite, R. (1953). Scientific Explanation. Cambridge: Cambridge University Press. [Versión castellana: Braithwaite, R. (1965). La explicación científica. V. Sánchez de Zavala (trad). Madrid: Tecnos].

Craig, E. (1986). The Practical Explication of Knowledge. Proceedings of the Aristotelian Society 87.

Dummett, M. (1978). Truth and Other Enigmas. Cambridge: Harvard University Press. [Versión castellana: Dummett, M. (1990). La verdad y otros enigmas. Alfonso Herrera Patiño (trad). México: Fondo de Cultura Económica].

Edwards, P. (1949). Russell's Doubts about Induction. Mind 68. Goldman, A. (1979). What is Justified Belief? En G. Pappas (ed). Justification and Knowledge. Dordrecht: Reidel.

Goodman, N. (1954). Fact, Fiction and Forecast. Londres: Athlone Press. [Versión castellana: Goodman, N. (2004). Hecho, ficción y pronóstico. Manuel Garrido (trad). Madrid: Síntesis].

Jardine, N. (1986). The Fortunes of Inquiry. Nueva York: Oxford University Press.

Mackie, J. L. (1974). The Cement of the Universe: A Study of Causation. Nueva York: Oxford University Press.

Papineau, D. (1987). Reality and Representation. Oxford: Basil Blackwell.

Shope, R. (1983). The Analysis of Knowing: A Decade of Research. Princeton: Princeton University Press.

Strawson, P. (1952). Introduction to Logical Theory. Londres: Methuen. [Versión castellana: Strawson, P. (1969). Introducción a una teoría de la lógica. J. Atelier (trad). Buenos Aires: Nova]. 
Van Cleve, J. (1984). Reliability, Justification and the Problem of Induction. Midwest Studies in Philosophy 10.

Williams, B. (1978). Descartes. The Proyect of Pure Enquiry. Londres: Pelican. [Versión castellana: Williams, B. (1995). Descartes: el proyecto de la investigación pura. Laura Benítez (trad). México: UNAM-IIF]. 